\title{
Clock mutations alter developmental timing in Drosophila
}

\author{
C. P. Kyriacou, \\ M. Oldroyd, \\ J. Wood, \\ M. Sharp and \\ M. Hill
}

Department of Genetics, University of Leicester, Leicester LE1 7RH, U.K.

The developmental time of period mutants in Drosophila melanogaster was monitored under different environmental conditions. We observed that the pers mutants, which have short $19 \mathrm{~h}$ circadian cycles, develop faster from eggs to adult than the wild-type: per $^{\mathrm{L}}$ mutants, which have long $28 \mathrm{~h}$ circadian rhythms, complete development more slowly than the wild-type. These results suggest that endogenous timers may be involved in regulating the development time of $D$. melanogaster.

\section{INTRODUCTION}

The period (per) gene plays an important role in biological timekeeping within Drosophila (Hall and Rosbash, 1988). Mutations at this locus in $D$. melanogaster can either speed up, slow down, or obliterate various types of biological rhythms. The per $^{\mathrm{s}}$ mutation for example shortens the normal free-running circadian period in both pupal/adult eclosion and individual adult locomotor activity patterns from 24 to $19 \mathrm{~h}$ (Konopka and Benzer, 1971). Also, per shortens the male fly's lovesong cycle, from 55 to $40 \mathrm{~s}$ (Kyriacou and Hall, 1980). The per ${ }^{\mathrm{L} 1}$ mutation lengthens both of these cycles, to $28 \mathrm{~h}$ and $80 \mathrm{~s}$ respectively, and the per ${ }^{01}$ mutants appear arrhythmic in both characters (Konopka and Benzer, 1971; Kyriacou and Hall, 1980). Furthermore, per $^{01}$ mutants are reported to have arrhythmic pupal heartbeats (Livingstone, 1981; Dowse et al., 1988). As the per mutations appear to affect a spectrum of temporally programmed phenotypes, we wondered whether these clock mutants would exhibit differences in development time, which at $25^{\circ} \mathrm{C}$ is approximately 10 days.

\section{METHODS}

\section{Strains}

The per ${ }^{\mathrm{s}}$, per $^{\mathrm{L} 1}$ and $p e r^{01}$ and $p e r^{+}$alleles were initially on genetic backgrounds in which the per alleles were coisogenic with respect to their autosomes, but not with respect to their $\mathrm{X}$ chromosome. We therefore repeatedly backcrossed the three mutants and the wild-type to a chromosome carrying a deletion of the period gene, $\mathrm{DF}(1) 64 \mathrm{j} 4$ (Hamblen et al., 1986). After 12 backcross generations we re-extracted the per alleles and made homozygous stocks of per ${ }^{\mathrm{L1}}, \mathrm{per}^{\mathrm{s}}, \mathrm{per}^{01}$ and $\mathrm{per}^{+}$. These stocks are therefore coisogenic except at the per locus.

\section{Environmental conditions}

The development time of period mutants in $D$. melanogaster was monitored under five different environmental conditions, four of which were under a constant temperature of $25 \pm 1^{\circ} \mathrm{C}$. These were constant darkness (DD), $12 \mathrm{~h}$ light, $12 \mathrm{~h}$ dark (LD12:12), constant bright light (LL) and constant very bright light (VLL). A fifth condition used was alternating $12 \mathrm{~h}$ light, dark cycles with a $12 \mathrm{~h} 25 \pm$ $1^{\circ} \mathrm{C} / 18 \pm 1^{\circ} \mathrm{C}$ temperature cycle superimposed (LD12:12T). The $25^{\circ} \mathrm{C}$ was synchronised to the $12 \mathrm{~h}$ light phase. The light/dark and dark/light transitions were at 9 p.m. and 9 a.m. respectively.

\section{Monitoring development}

Eggs were collected from fertilised females under LD12:12 conditions. Virgin females had been 
collected simultaneously from the four per genotypes and aged for 3 days before being paired with males. They were allowed to mate for two days and then 50 fertilised females were placed in a bottle and allowed to lay eggs for $48 \mathrm{~h}$ in order to acclimatize them to their egg-laying media. During this period fresh egg-laying plates were provided every $3 \mathrm{~h}$ during the light phase. After this "prelaying" period it was found that enough eggs could be obtained simultaneously from each genotype in one $2 \mathrm{~h}$ egg laying session to set up each experiment. Five experimental conditions were used, LD12:12, LD12:12T, DD, LL and VLL (see above). To examine the duration of the embryonic stage, rows of 20 freshly laid eggs were placed on glass plates containing agar. The eggs were monitored every $2 \mathrm{~h}$ until all larvae had hatched. Eggs were monitored under LL and approximately 200 eggs were observed for each genotype.

To examine the duration of the larval period, first instar larvae were obtained simultaneously from the four per genotypes by taking only those individuals which had hatched within $2 \mathrm{~h}$ of each other. Consequently our larval duration measure is largely uncontaminated by any effects of the per alleles on egg hatching rate. Using a plastic drinking straw, 10 larvae were scooped up from an egg laying plate, and placed in a food vial containing a standard amount of Drosophila medium according to Kyriacou (1985). As many vials as possible were set up depending on the number of larvae available, but a minimum of 100 larvae from each genotype were plated out in this way for the LD12:12, DD and LL experiments, and 250 for the LD12:12T and VLL experiments. The vials were then placed in one of the five environmental conditions, and monitored until puparium formation, and adult eclosion. When observations were made in darkness as in the LD12:12, LD12:12T and DD conditions a lamp using a filter (Wratten No. $87 \mathrm{C}$ ) which transmitted wavelengths greater than $600 \mathrm{~nm}$ was used. Drosophila are insensitive to red light of this wavelength (Frank and Zimmerman, 1969; Kyriacou and Burnet, 1979).

In the LL and VLL conditions, flies were monitored under constant bright light. In the LL condition, the light was generated from an incubator and the photon fluence rate (pfr) measured as $3 \mu \mathrm{mol} \mathrm{m} \mathrm{m}^{-2} \mathrm{~s}^{-1}$. In the VLL condition the pfr was $100 \mu \mathrm{mol} \mathrm{m}^{-2} \mathrm{~s}^{-1}$. Normal laboratory lighting has a pfr of $1.5 \mu \mathrm{mol} \mathrm{m} \mathrm{m}^{-2} \mathrm{~s}^{-1}$. From the experimental design described above we were able to obtain measurements for the duration of the embryonic, the larval and a combined measure for the duration of the larval and pupal stages.

\section{Statistical analysis}

Statistical analyses of the development time of per mutants compared to the wild-type for different developmental stages, were performed using the Kolmogorov Smirnov two sample test (Siegel, 1956) to compare the developmental speed of each mutant vs. the wild-type. As an additional test, a two-way ANOVA was performed with genotypes as one factor and time as the other. The cumulative number of individuals per egg laying tray, or per vial, which completed each developmental stage was used as the dependent variable. Although the cumulative data are not independent, the ANOVA can pick out genotype and interaction effects and, when used in addition to the nonparametric test above, is useful in interpreting the results. Analysis of variance was also performed on the final numbers of larvae pupating in order to examine larval viability.

\section{RESULTS}

\section{Egg-hatching rate}

The results of the Kolmogorov-Smirnov tests, where each per mutant was compared to the wildtype are shown in table 1 . The per ${ }^{\mathrm{s}}$ eggs hatched significantly faster than the wild-type eggs $(P<$ $0.01)$. In the ANOVA the genotype $(F=4.13 P<$ $0.01)$ and interaction effects $(F=2.2 \quad P<0.05)$ were significant. The Newman-Keuls a posteriori procedure confirms that the per $^{\mathrm{s}}$ genotype hatches significantly faster than $\operatorname{per}^{+}(P<0 \cdot 01)$ with no significant differences between the other genotypes. Table 2 gives the mean $( \pm$ SEM $)$ number of

Table 1 Statistical analysis of the development time of each per mutant compared to the wild-type

\begin{tabular}{lllll}
\hline $\begin{array}{l}\text { Developmental } \\
\text { stage }\end{array}$ & Conditions & per & per & per \\
\hline Embryonic & LL & fast* & ns & ns \\
Larval & DD & ns & slow** & ns \\
& LD12:12 & ns & slow** & ns \\
& LD12:12T & fast* & slow** & slow* \\
& LL & ns & slow** & slow** \\
& VLL & fast** & slow** & fast* \\
Combined & DD & fast* & slow** & fast** \\
larval+pupal & LD12:12 & fast** $^{*}$ & slow** & ns \\
& LD12:12T & fast** $^{* *}$ & slow** & slow** \\
& LL & fast** & slow** & fast** \\
& VLL & fast** $^{* *}$ & slow** & fast**
\end{tabular}

$* P<0.05$

** $P<0.01$. 
Table 2 The mean number ( \pm SEM) of individuals out of 10 completing embryonic, larval, and pupal development at specific time points. The results for the three time points given in the LD12:12T for the combined larval and pupal condition illustrate a significant interaction of genotypes $\times$ time (see text)

\begin{tabular}{|c|c|c|c|c|c|c|}
\hline $\begin{array}{l}\text { Developmental } \\
\text { stage }\end{array}$ & Conditions & $\begin{array}{l}\text { Time } \\
\text { point }\end{array}$ & per $^{+}$ & $p e r^{s}$ & $p e r^{01}$ & $p e r^{\mathrm{L} 1}$ \\
\hline Embryonic & & 2 & $2.95 \pm 0.41$ & $4.90 \pm 0.66$ & $3 \cdot 40 \pm 0 \cdot 50$ & $2 \cdot 70 \pm 0 \cdot 24$ \\
\hline Larval & $\begin{array}{l}\text { DD } \\
\text { LD12:12 } \\
\text { LD12:12T } \\
\text { LL } \\
\text { VLL }\end{array}$ & $\begin{array}{l}3 \\
3 \\
2 \\
3 \\
2\end{array}$ & $\begin{array}{l}8 \cdot 20 \pm 0.29 \\
4 \cdot 10 \pm 0.73 \\
5 \cdot 28 \pm 0.43 \\
4.90 \pm 0.64 \\
1.60 \pm 0.37\end{array}$ & $\begin{array}{l}9 \cdot 00 \pm 0.36 \\
3 \cdot 10 \pm 0.48 \\
6.44 \pm 0.64 \\
4 \cdot 10 \pm 0.67 \\
3.96 \pm 0.31\end{array}$ & $\begin{array}{l}8 \cdot 60 \pm 0 \cdot 30 \\
4 \cdot 20 \pm 0 \cdot 44 \\
4 \cdot 00 \pm 0 \cdot 47 \\
2 \cdot 30 \pm 0 \cdot 30 \\
2 \cdot 20 \pm 0 \cdot 42\end{array}$ & $\begin{array}{l}5 \cdot 00 \pm 0.79 \\
2 \cdot 20 \pm 0.82 \\
1 \cdot 84 \pm 0.33 \\
2 \cdot 30 \pm 0.80 \\
0.08 \pm 0.06\end{array}$ \\
\hline $\begin{array}{l}\text { Combined } \\
\text { larval + pupal }\end{array}$ & $\begin{array}{l}\text { DD } \\
\text { LD12:12 } \\
\text { LD12:12T } \\
\text { LD12:12T } \\
\text { LD12:12T } \\
\text { LL } \\
\text { VLL }\end{array}$ & $\begin{array}{l}3 \\
3 \\
1 \\
2 \\
3 \\
3 \\
3\end{array}$ & $\begin{array}{l}4 \cdot 50 \pm 0 \cdot 50 \\
6 \cdot 22 \pm 0 \cdot 72 \\
0 \cdot 44 \pm 0 \cdot 14 \\
3 \cdot 40 \pm 0 \cdot 39 \\
7 \cdot 12 \pm 0 \cdot 36 \\
5 \cdot 40 \pm 0 \cdot 54 \\
4 \cdot 20 \pm 0 \cdot 55\end{array}$ & $\begin{array}{l}5 \cdot 20 \pm 0.44 \\
8 \cdot 30 \pm 0 \cdot 50 \\
2 \cdot 68 \pm 0 \cdot 50 \\
4 \cdot 68 \pm 0.64 \\
5 \cdot 56 \pm 0.69 \\
6 \cdot 10 \pm 0.66 \\
5 \cdot 40 \pm 0.44\end{array}$ & $\begin{array}{l}6 \cdot 30 \pm 0.52 \\
8 \cdot 29 \pm 0.68 \\
1 \cdot 84 \pm 0 \cdot 39 \\
3 \cdot 88 \pm 0.46 \\
5 \cdot 32 \pm 0.51 \\
7 \cdot 00 \pm 0.47 \\
6 \cdot 28 \pm 0.56\end{array}$ & $\begin{array}{l}0 \cdot 50 \pm 0 \cdot 27 \\
5 \cdot 80 \pm 0.61 \\
0 \\
0 \cdot 20 \pm 0 \cdot 10 \\
1 \cdot 36 \pm 0 \cdot 13 \\
4 \cdot 20 \pm 0 \cdot 27 \\
1 \cdot 56 \pm 0.66\end{array}$ \\
\hline
\end{tabular}

eggs which had hatched by the second observation period $(20 \cdot 5 \mathrm{~h}$ after egg laying). At this point one can see clearly that more per $^{\mathrm{s}}$ eggs have hatched compared to the other genotypes, this difference being significant when comparing $\operatorname{per}^{\mathrm{s}}$ to $\mathrm{per}^{+}(P<$ $0.01)$. The significant interaction is due to all the genotypes having the same scores at the last observation period, i.e., all eggs had hatched. Therefore there is some evidence that even in the first $20-24 \mathrm{~h}$ of development, the per mutants may be having some effect on the duration of the embryonic stage. The direction of the difference produced in per $^{\text {s }}$ eggs parallels the effects of this mutation on circadian and ultradian cycles.

\section{Larval duration}

The Kolmogorov-Smirnov test reveals that per $^{\mathrm{L} 1}$ flies remained significantly longer in the larval stage than the wild-type under all environmental conditions (see table 1 and fig. 1 for examples). The per $^{\mathrm{s}}$ mutants appear to develop slightly faster than the wild-type during the larval stage under some conditions (see table 1 and fig. 1) whereas the per $^{01}$ larval development time, appears quite variable when compared to $\mathrm{per}^{+}$. The ANOVAS for these data all give significant genotype and interactions effects (except for the interaction term in the LD12:12 condition). Inspecting the means for some of the salient time points in table 2 , it is clear that $p e r^{\mathrm{L} 1}$ flies lag far behind the wild-type during the larval period under all conditions. The $\mathrm{per}^{\mathrm{s}}$ flies appear to develop faster than the wildtype in the LD12:12T $(P<0.01)$, VLL, $(P<0.01)$ and also in DD, but this latter effect narrowly misses significance using the conservative New-
man-Keuls test. This pattern of results confirms that of the Kolmogorov-Smirnov test. In addition, in the per $^{01}$ vs. per ${ }^{+}$comparison, the results of the Newman-Keul's test supports those of the nonparametric test with per $^{01}$ developing significantly more slowly than the wild-type in LD12:12T and LL $(P<0.01)$ and significantly more quickly in VLL $(P<0.05)$. The significant interaction terms in the ANOVA are due to the per ${ }^{\mathrm{L} 1}$ genotype "catching up" with the others at the later time points. No significant interactions are observed in the early time points between the four genotypes.

\section{Combined larval and pupal duration}

When the combined measures of larval and pupal duration are examined we see that $p e r^{L_{1}}$ flies take significantly longer than the wild-type to complete development, and per $^{s}$ flies develop significantly faster than wild-type using the KolmogorovSmirnov procedure (table 1 and fig. 1). The development of per $^{01}$ flies again appears variable, being significantly slower under LD12:12T, and faster under VLL, LL and DD. The ANOVA results again largely confirm the non-parametric test. Significant genotype effects $(P<0.01)$ are observed in all conditions, and interaction effects in the DD, LD12: 12T $(P<0.01)$ and VLL $(P<0.05)$ conditions. The LD12:12T interaction is due to the per ${ }^{+}$means criss-crossing with the per $^{01}$ and $p^{\mathrm{s}} \mathrm{r}^{\mathrm{s}}$ means in the first three time points: per $^{\mathrm{s}}$ and per $^{01}$ eclose significantly faster than per $^{+}$in the first two observations periods, but per" "catches up" and overtakes them at the third observation (see table 2 and fig. 1). All the other interactions are caused by the slower per $^{\mathrm{L} 1}$ genotypes "catching 

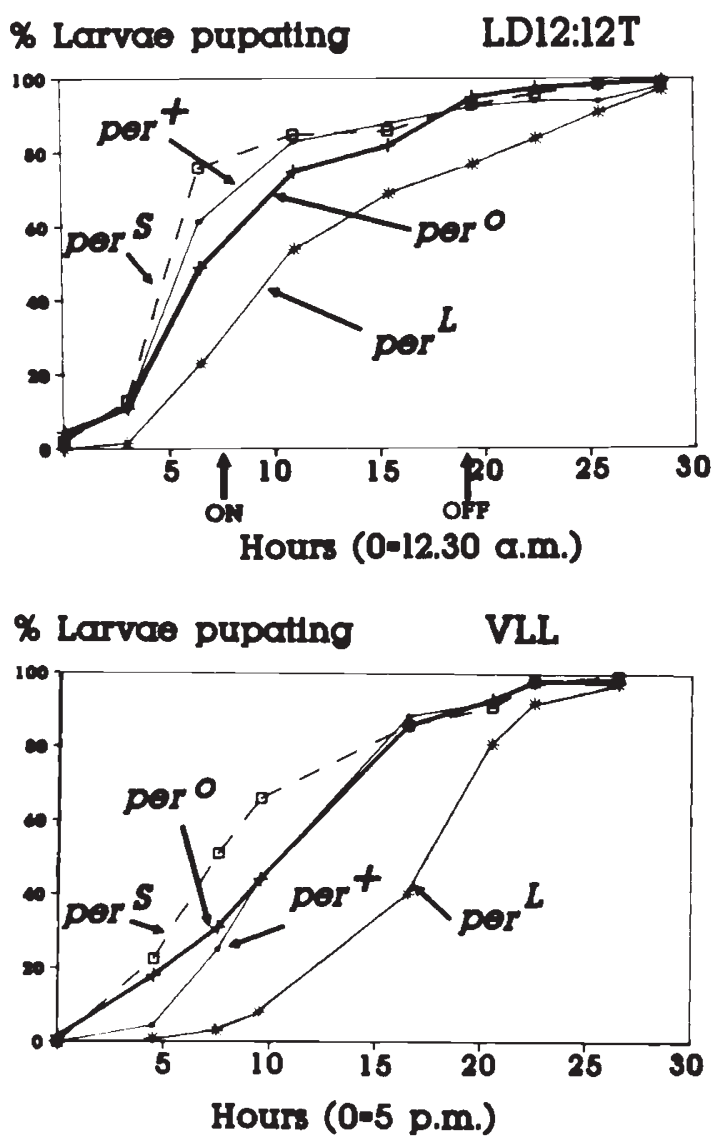

\% Adults emerging LD12:12T

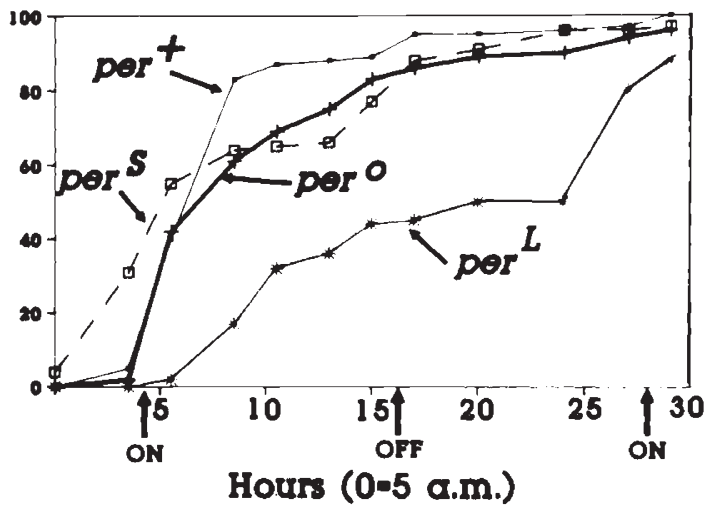

\% Adults emerging VLL

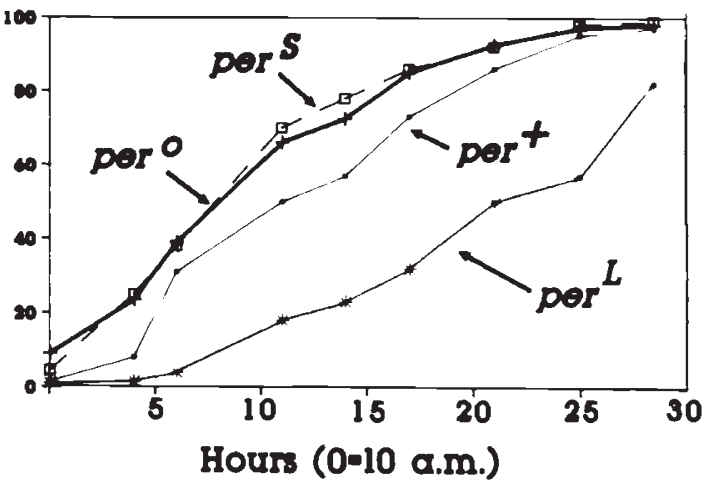

Figure 1 Developmental time in per variants. The cumulative percentage of larvae pupating and adults emerging are plotted over time. The data for the LD12:12T and VLL conditions are shown. The arrows at the bottom of the graph in the LD12:12T condition denote the times of lights "on" and lights "off" (on at 9 a.m. off at 9 p.m.). The real time corresponding to ON is also given. Note the sudden emergence of adult flies through "gates" between 7-10 a.m. and their sudden pupation between 3-7 a.m., in LD12:12T. This can be compared with the VLL profiles, where flies pupate and emerge more gradually through out the day, because eclosion and pupation rhythms have been damped out by the bright light.

up" with the others in the later time points. Inspecting table 2 , it is clear that $p^{\mathrm{s}}$ flies eclose significantly faster than $\mathrm{per}^{+}$, and $\mathrm{per}^{\mathrm{L1}}$ eclose significantly more slowly than per $^{+}(P<0.01$ all a posteriori comparisons). per ${ }^{01}$ flies eclose significantly faster than per $^{+}$in DD, LL, and VLL, $(P<0.01)$, but they are slower in LD12:12T $(P<0.01$ at one third observation). These results also confirm the Kolmogorov-Smirnov pattern.

\section{Larval viability}

Table 3 gives the mean numbers of larvae per vial which pupated. Two-way ANOVA gave significant effects of environmental conditions $(F=16 \cdot 13$, df $=4,418 P<0.01)$ and genotypes $(F=3.33$, df $=$ $3,418 P<0.05)$. From inspection of the means in table 2 it appears that the VLL conditions are acting to reduce larval viability, and that the $p^{\mathrm{s}}$ larvae are generally the most viable genotype, although this advantage is reduced under the two "entrainment" conditions, LD12:12 and LD12:12T. Interestingly, per $^{01}$ larvae are no less viable than per $^{+}$.

Table 3 Viability of larvae under different environmental conditions. The numbers represent the mean number of larvae out of 10 which reached the pupal stage

\begin{tabular}{|c|c|c|c|c|c|}
\hline Conditions & per $^{+}$ & $p e r^{\mathrm{L} 1}$ & $p_{e r}{ }^{s}$ & per $^{01}$ & $\begin{array}{l}\text { Grand } \\
\text { means }\end{array}$ \\
\hline LD12: $12 \mathrm{~T}$ & $8 \cdot 76$ & $8 \cdot 72$ & $8 \cdot 72$ & $9 \cdot 0$ & $8 \cdot 80$ \\
\hline $\mathrm{LL}$ & $8 \cdot 36$ & $8 \cdot 54$ & $9 \cdot 96$ & $9 \cdot 13$ & $9 \cdot 00$ \\
\hline VLL & $6 \cdot 32$ & $6 \cdot 84$ & $7 \cdot 80$ & $7 \cdot 28$ & $7 \cdot 06$ \\
\hline LD12: 12 & $8 \cdot 56$ & $8 \cdot 36$ & $8 \cdot 44$ & $8 \cdot 2$ & $8 \cdot 39$ \\
\hline $\mathrm{DD}$ & $9 \cdot 00$ & $8 \cdot 40$ & $9 \cdot 70$ & $9 \cdot 10$ & $9 \cdot 05$ \\
\hline Grand means & $8 \cdot 20$ & $8 \cdot 17$ & $8 \cdot 92$ & $8 \cdot 54$ & $8 \cdot 46$ \\
\hline
\end{tabular}




\section{DISCUSSION}

The different environmental conditions we used were designed to bypass interference from the circadian clock on our measures of development times. The circadian clock "gates" adult emergence from the pupa in that the majority of adults which eclose in a given $24 \mathrm{~h}$ period emerge in a narrow time band, or "gate", around dawn (Pittendrigh, 1974). When flies are exposed to light and dark then placed under DD, the period of the circadian clock free-runs with the genotype specific period (Konopka and Benzer, 1971). Thus although the first instar larvae were all gathered within two hours of hatching, by the time they eclose as adults, (i.e., 10 days later at $25^{\circ} \mathrm{C}$ ) their emergence may be spread around two eclosion "gates". These will occur $19 \mathrm{~h}$ apart in per flies, $24 \mathrm{~h}$ apart in per $^{+}$ flies and $28 \mathrm{~h}$ apart in per $^{\mathrm{L} 1}$ flies. Consequently we would predict that compared to the wild-type, per $^{\mathrm{L} 1}$ flies would on average develop more slowly, and $p^{\text {s }}{ }^{\text {s flies }}$ would develop more quickly. In LD12: 12, the three genotypes, per $^{\mathrm{S}}$, per ${ }^{\mathrm{L} 1}$ and per $^{+}$ are all entrained to the $24 \mathrm{~h}$ cycle (Konopka, 1972), so, any differences between the mutants development time and the wild-type will not be due to the different periodicities of the mutants, although the rhythm of each mutant may lock on to a slightly different phase (Konopka, 1972). The eclosion of per $^{01}$ mutants does not entrain under LD12:12 but it will entrain if a temperature cycle is also imposed (Konopka, 1972). Therefore the LD12:12T condition is designed to entrain per ${ }^{01}$ flies, and in this environment all four per genotypes have prominent eclosion gates which occur every $24 \mathrm{~h}$.

Under LL and VLL conditions $p e r^{+}$per $^{\mathrm{L} 1}$ and per $^{\text {s }}$ become arrhythmic (Konopka, 1972; Kyriacou and Hall, 1980), and the absence of eclosion "gates" allows the development time of these three variants to be directly compared with $p^{01}$. Thus under these conditions, differences in the period and the phase of cycles of the four per variants are eliminated. We tested all four strains in the LL and VLL conditions in preliminary experiments to see whether they produced a "damping" out of the eclosion rhythm. Both lighting conditions succeeded, giving eclosion profiles of per ${ }^{+}$per $^{\mathrm{s}}$ and per $^{\mathrm{L} 1}$ flies which were very similar to $\operatorname{per}^{01}$ (data not shown).

From our results we can therefore conclude that in conditions where differences in the circadian periods of per ${ }^{\mathrm{s}}$, per ${ }^{+}$, per $^{\mathrm{L} 1}$ and per $^{01}$ are experimentally bypassed (as in conditions LD12:12T, LL and VLL) the combined larval and pupal development times of the mutants appear to have been altered. The most definitive results come from the arrhythmic LL and VLL conditions, because there are neither phase nor period differences between the per variants. The direction of differences in $p^{\mathrm{L}} \mathrm{L}^{\mathrm{L}}$ and $p e r^{\mathrm{S}}$ shows striking parallels with the effects of these mutations on circadian and ultradian cycles. The results with per $^{01}$ mutants suggest that under constant lighting conditions (either constant light or dark), they generally develop faster than the wild-type. However when entraining light and temperature cycles are imposed, they slow down compared to the wild-type.

An additional result which is worth noting is the larval viability measure. Clearly under VLL conditions larval viability is considerably reduced. Perhaps this is a byproduct of creating an "arrhythmic" phenotype in per ${ }^{\mathrm{s}}$, per $^{\mathrm{L} 1}$ and per $^{+}$flies, but this is unlikely given that the viability of the arhythmic per ${ }^{01}$ larvae is also reduced. This poor viability may simply be a consequence of a very bright light-induced physiological "stress". The generally superior per $^{\mathrm{s}}$ larval viability is not observed when per $^{\mathrm{s}}$ individuals are entrained to a LD12:12 cycle. When per $^{\mathrm{s}}$ flies are released from such environmental constraints as they are in DD, LL, and VLL, their viability increases, suggesting that the circadian clock may also play a role in this important fitness character.

Given that per $^{\mathrm{s}}$ flies appear to develop faster than the other genotypes, and also have superior larval viability, the question arises as to what would happen if the per ${ }^{\text {s }}$ allele was allowed to compete in a population cage with $\mathrm{per}^{+}$. Certainly one might expect $p e r^{\mathrm{s}}$ flies to compete quite successfully given this pre-imaginal fitness advantage. We have recently initiated a population study and will monitor changes in gene frequencies of $p e r^{\mathrm{s}}, p^{\mathrm{L}} \mathrm{L}^{\mathrm{L}}$, and per $^{01}$ in competition with per $^{+}$.

The mutant circadian phenotypes observed in per $^{\mathrm{s}}$, per $^{\mathrm{L} 1}$ and per $^{01}$ flies are due to changes in the per gene's proteoglycan-like gene product (Reddy et al., 1986; Jackson et al., 1986; Yu et al., 1987 and Baylies et al., 1987). The mutant proteoglycans may alter the pattern of intercellular coupling between cells by affecting gap junctional communication (Spray et al., 1987 and Bargiello et al., 1987) Gap junctions appear to be important during development, because disturbing them can impail pattern formation (Warner, 1985). Furthermore restriction of the developmental fates of cells corre. lates with changes observed in their pattern of gar junctional communication (Serras and Van der Bigelaar, 1987; Lo and Gilula, 1979). Therefore it is conceivable that the rapid intercellular 
communication demonstrated between per $^{\text {s }}$ cells (Bargiello et al., 1987) may also lead to the faster development we observe in our experiments, with obvious implications for per $^{\mathrm{L} 1}$ development.

Alternatively, if the circadian clock of Drosophila is generated by a network of coupled oscillators, the per mutants may produce their circadian effects by altering the coupling between tonically active cells (Dowse, Ringo and Hall, 1987; Dowse and Ringo, 1987; Bargiello et al., 1987). If this clock also regulates development time, then this may explain why per ${ }^{\mathrm{s}}$ develop faster and $p^{2}{ }^{\mathrm{L} 1}$ develop slower than the wild-type. Perhaps the effects we see with per mutant development times might be due to the clock playing a role in the cell division mechanism. In lower eukaryotes, biochemical oscillations are important in cell cycle control and have been repeatedly suggested to represent the high frequency "ticks" of the circadian clock (Chance et al., 1964; Borteaux et al., 1975; Lloyd and Edwards, 1984). Thus there appears to be a relationship between biochemical oscillations, cell cycle and the circadian clock in these organisms. Furthermore, endogenous timers have also been invoked to explain the control of various developmental processes in higher organisms (Cooke and Zeeman, 1976; Snow and Tam, 1980).

The per transcript and gene product are observed at embryonic, pupal and adult stages (James et al., 1986; Liu et al., 1988; Siwicki et al., 1988; Bargiello and Young, 1984). However, the per protein is required only at the adult stage in order to induce circadian rhythms (Ewer et al., 1988). Thus the per gene may have other functions at the earlier developmental stages and our results suggest that one of these roles may be to regulate the timing of development. We detect effects of the per mutations at the embryonic, larval and also in the pupal stages, and further experiments are in progress to examine how the per mutants produce these changes in development time.

Acknowledgements We thank Jeff Hall and Ron Konopka and an anonymous reviewer for comments on this manuscript. We also thank Professor Caligari for suggesting the ANOVA. The work was funded by an SERC project grant to C.P.K.

\section{REFERENCES}

BARGIELlo, T. A. AND YOUNG, M. W. 1984. Molecular genetics of a biological clock in Drosophila. Proc. Natl Acad. Sci. USA., 81, 2142-2146.
BARGIELlO, T. A., JACKSON, F. R. AND YOUNG, M. W. 1984 Restoration of circadian behavioural rythms by gene transfer in Drosophila. Nature, 312, 752-754.

BARgiello, T. A., SAEZ, T. A., BAYlies, M. K., GASiC, G., YOUNG, M. W. AND SPRAY, D. C. 1987. The Drosophila gene per affects intercellular junctional communication. Nature, 328, 686-691.

BAYLIES, M. K., BARGIELlo, T. A., JACKSON, F. R. AND YOUNG, M. W. 1987. Changes in abundance or structure of the per gene product can alter periodicity of the Drosophila clock. Nature, 326, 390-392.

BORTEAUX, A., GOLDBEATER, A. AND HESS, B. 1975. Control of oscillating glycolysis of yeast by stochastic, periodic and steady source of substrate: A model and experimental study. Proc. Natl Acad. Sci. USA., 72, 3829-3833.

CHANCE, B., EASTBRoOK, R. W. AND GHOSH, A. 1964. Damped sinusoidal oscillations of cytoplasmic reduced pyridine nucleoutides in yeast cells. Proc. Natl Acad. Sci. USA., 51, 1244-1251.

COOKE, J. AND ZEEMAN, E. C. 1976. A clock and wavefront model for control of the number of repeated structures during animal morphogenesis. J. Theoret. Biol. 58, 455-476.

DOWSE, H. B., HALL, J. C. AND RINGO, J. M. 1987. Circadian and ultradian rhythms in period mutants of Drosophila melanogaster. Behav. Genet., 17, 19-35.

DOWSE, H. B. AND RINGO, J. M. 1987. Further evidence that circadian rhythms in Drosophila are a population of coupled ultradian oscillators. J. Biol. Rhythms, 2, 65-76.

DOWSE, H. B., KASS, L. AND RINGO, J. M. 1988. Studies on a congenital heart defect in Drosophila. Behav. Genet., 18, s714-715.

EWER, J., ROSBASH, M. AND HALL, J. C. 1988. An inducible promotor fused to the period gene in Drosophila conditionally rescues adult per-mutant arrhythmicity. Nature, $333,82-84$

FRANK, K. D. AND ZIMMERMAN, W. F. 1969. Action spectra for phase shifts of a circadian rhythm in Drosophila. Science, 168, 688-689.

HALL, J. C. AND ROSBASH, M. 1988. Mutations and molecules influencing biological rhythms. Ann. Rev. Neurosci., 11, 373-393.

HAMBLEN, M., ZEHRING, W. A., KYRIACOU, C. P., REDDY, P., YU, Q., WHEELER, D. A., ZWEIBEL, O. L. J., KONOPKA, R. J., ROSBASH, M. AND HALL, J. C. 1986. Germ-line transformation involving DNA from the period locus in Drosophila melanogaster. Overlapping genomic fragments that restore circadian and ultradian rhythmicity to per ${ }^{0}$ and per mutants. J. Neurogenet., 3, 249-291.

JACKSON, F. R., BARGIELLO, T. A., YUN, S. H. AND YOUNG, M. W. 1986. Product of per of Drosophila shares homology with proteoglycans. Nature, 320, 185-188.

JAMES, A. A., EWER, J., REDDY, P., HALL, J. C. AND ROSBASH, M. 1986. Embryonic expression of the period clock gene of Drosophila melanogaster. EMBO. J., 5, 2313-2320.

KONOPKA, R. J. 1972. Circadian Clock Mutants of Drosophila melanogaster. Ph.D. Thesis. California Institute of Technology.

KONOPKA, R. J. AND BENZER, S. 1971. Clock mutants of Drosophila melanogaster. Proc. Natl Acad. Sci. USA, 68, 2112 2116

KYRIACOU, C. P. AND HALL, J. C. 1980. Circadian rhythm mutations in Drosophila affect short-term fluctuations in the male's courtship song. Proc. Natl Acad. Sci. USA, 77, 6929-6933.

KYRIACOU, C. P. 1985. Long term ebony polymorphisms: a comparison of the contributions of behavioural and nonbehavioural fitness characters. Behav. Genet. 15, 165-180. 
KYRIACOU, C. P. AND BURNET, B. 1979. Genetic analysis of phototaxis near the upper limit of the visual spectrum in D. melanogaster. Behav. Genet., 123-128.

LIU, X., LORENZ, L., YU, Q., HALL, J. C. AND ROSBASH, M. 1988. Spatial and temporal expression of the period gene in Drosophila melanogaster. 1988. Genes \& Development, 2, 228-238.

LiVingstone, M. S. 1981. Two mutations in Drosophila affect the synthesis of octopamine, dopamine and serotonin by altering the activities of two different amino-acid decarboxylases. Neurosci. Abst., 8, 384.

LLOYD, D. AND EDWARDS, S. W. 1984. Epigenetic oscillation during the cell cycles of lower eukaryotes are coupled to a clock. In Edmunds, L. N. (ed.) Cell Cycle Clocks, Marcel Dekker, New York, pp. 27-46.

LO, C. W. AND GILULA, N. B. 1979 Gap junctional communication in the post-implantation mouse embryo. Cell, 18,411422.

PITTENDRIGH, C. S. 1974. Circadian oscillations in cells and the circadian organisation of multicellular systems. In Schmit, F. O. and Worden, F. G. (eds) The Neurosciences: Third Study Program, Cambridge, MIT Press, pp. 437-458.

REDDY, P., JACQUIER, A. C., ABOVICH, N., PETERSEN, G. AND ROSBASH, M. 1986. The period clock locus of $D$. melanogaster codes for a proteoglycan. Cell, 46, 53-61.
SERRAS, F. AND VAN DEN BIGELAAR, J. A. M. 1987. Is a mosaic embryo also a mosaic of communciation compartments? Dev. Biol., 120, 132-138.

SIEGEL, S. 1956. Nonparametric Statistics for the Behavioural Sciences. Tokyo, McGraw-Hill.

SIWICKI, K. K., EASTMAN, C., PETERSEN, G., ROSBASH, M. AND HALL, J. C. 1988. Antibodies to the period gene product of Drosophila reveal diverse tissue distribution and rhythmic changes in the visual system. Neuron, 1, 141-150.

SNOW, M. H. L. AND TAM, P. L. 1980. Timing in embryological development. Nature, 286, 107.

SPRAY, D. C., FUJITA, M., SAEZ, J. C., CHOI, H., WATANABE, T., HEITZBERG, L., ROSENBERG, C. AND REID, L. M. 1987. Proteoglycans and glycasominoglycans induce gap junction synthesis and function in primary liver cell cultures. J. Cell. Biol., 105, 541-551.

WARNER, A. 1985. The role of gap junctions in amphibian development. J. Embr. Exp. Morph. Suppl., 89, 365-380.

YU, Q., JACQUIER, A. C., CITRI, Y. AND COLOT, H. M. 1987. Molecular mapping of point mutations in the period gene that stop or speed up biological clocks in Drosophila melanogaster. Proc. Natl Acad. Sci. USA, 84, 784-788. 